\title{
Editorial
}

\section{Alveolitis: the key to the interstitial lung disorders}

The interstitial lung diseases are a heterogeneous group of chronic, non-infectious, non-malignant disorders that affect primarily the alveolar structures. ${ }^{1-5}$ The spectrum of disease included under this heading is enormous-at least 130 different interstitial lung diseases have been described (see references 1,5 for the current list). Most of these diseases, however, are relatively rare; the common interstitial disorders are those resulting from inhalation of inorganic or organic dusts, sarcoidosis, idiopathic pulmonary fibrosis, and the interstitial lung diseases associated with the collagen-vascular disorders. ${ }^{1}$

While diagnosis is not usually a major problem, the management of patients with interstitial lung disease presents a difficult challenge. These diseases are generally progressive, but in a baffling, often intermittent, stop-start fashion. More importantly, it is now apparent that conventional, clinical, radiological, and physiological assessments bear little relationship to staging the activity of these disorders, thus frustrating the clinician's attempt to make rational therapeutic decisions. ${ }^{156}$

All this is changing, however. Through the work of many laboratories throughout the world, it is now recognised that, independent of the type of disease or specific aetiology, the earliest manifestation of interstitial disease is an "alveolitis"- the accumulation of inflammatory and immune effector cells within the alveolar structures. ${ }^{13-5}$ 7-10 The importance of the alveolitis is simply stated: while it is clear that the interstitial lung diseases are characterised by a variety of derangements to the cells and connective tissue matrix that comprise the alveolar structures, it is now recognised that it is the alveolitis that causes these derangements. As we will see, the concept of "alveolitis" has caused a revolution in thinking that has completely changed the clinical approach to staging and treating patients with interstitial lung disease.

\section{Lessons from morphology}

While the concept of alveolitis may appear "new",

Address for reprint requests: Dr RG Crystal, 6D06, Building 10, National Institutes of Health, Bethesda, Maryland 20205, USA. it has actually been with us for some time. For years, morphologists have been pointing out that, besides the fibrosis and cystic lesions that characterise the late stages of these diseases, early on there are accumulations of macrophages, lymphocytes and often, polymorphonuclear leucocytes. An excellent example of this is idiopathic pulmonary fibrosis (IPF), a disease for which Scadding championed the term "fibrosing alveolitis", perceptively implying that not only is this disease characterised by fibrosis, but it is an alveolitis that causes the fibrosis and hence, the derangements of the alveolar structures. ${ }^{11} 12$

There is compelling morphological evidence that the alveolitis precedes the derangements to the alveolar structures that characterise interstitial disease. In sarcoidosis, Carrington et $a^{13}$ have shown that almost all patients with sarcoidosis have an alveolitis. Rosen and colleagues have demonstrated that $100 \%$ of patients with radiographic features of hilar adenopathy without parenchymal changes have granulomata, the result of alveolitis. ${ }^{14}$ Convincingly, Takahashi et al, ${ }^{15}$ Telium et al, ${ }^{16}$ Judd et al, ${ }^{17}$ and Rosen et al ${ }^{18}$ have all presented evidence that a mononuclear cell alveolitis precedes granuloma formation in sarcoidosis. Consistent with this concept, Lacronique and colleagues have used a quantitative point counting technique to demonstrate an inverse relationship between alveolitis and granuloma in this disease. ${ }^{19}$

There is also ample evidence that an alveolitis is the earliest manifestation of IPF. 382021 Probably the most convincing data come from the studies of Carrington and Gaensler who have shown that patients with morphological evidence of desquamative interstitial pneumonitis (early IPF) are those who can resolve completely. ${ }^{20}$ Conversely, those with usual interstitial pneumonitis (late IPF), do not. Alveolitis is also prominent in the descriptions of biopsies of patients with early hypersensitivity pneumonitis (extrinsic allergic alveolitis), ${ }^{22}{ }^{23}$ asbestosis, ${ }^{24}$ silicosis, ${ }^{25} 26$ and the interstitial lung diseases associated with the collagen vascular disorders. ${ }^{27}$ Furthermore, a variety of experimental animal models of interstitial lung disease including asbestosis, ${ }^{28}{ }^{29}$ silicosis, ${ }^{30}$ and hypersensitivity pneumonitis, ${ }^{31}$ have also emphasised that the earliest morphological findings are an alveolitis. 


\section{Methods to evaluate alveolitis in humans}

While intellectually satisfying, the concept of the central role of the alveolitis would not be much of a key to the interstitial disorders unless the alveolitis could be evaluated routinely in these patients. Alveolitis can be evaluated by open lung biopsy, but not all patients are biopsied in this fashion, open biopsy is rarely carried out more than once during a patient's course, and quantitation of the number and types of effector cells present in biopsy material is tedious and not routinely available. ${ }^{13}$

To move the concept of alveolitis to that of useful routine clinical practice, it was necessary to have methods by which the clinician could safely and accurately evaluate the alveolitis on a repetitive basis. Until the mid 1970s this concept was only a theoretical hope, but with the development of two techniques-bronchoalveolar lavage ${ }^{72}$ and gallium$67\left({ }^{67} \mathrm{Ga}\right)$ scanning ${ }^{33} 34$ _repetitive, quantitative evaluation of inflammatory and immune processes in the alveolar structures became possible on a routine basis.

\section{BRONCHOALVEOLAR LAVAGE}

This method permits repetitive sampling of the inflammatory and immune effector cells and mediators in the fluid lining the epithelium of the alveolar structures. ${ }^{3} 7$ The technique is a simple extension of routine fibreoptic bronchoscopy. After local anaesthesia, the fibreoptic bronchoscope is wedged into a distal bronchus, usually in the lingula or right middle lobe (all lobes can be used, but the yield is somewhat greater in these sites). Following the original method developed by Reynolds and colleagues, ${ }^{35}$ we use a total of $100 \mathrm{ml}$ of $0.9 \%$ sterile saline (in five $20 \mathrm{ml}$ aliquots) for each site up to a maximum of three sites -that is, $300 \mathrm{ml}$ total. Each aliquot of saline is flushed through the bronchoscope and immediately aspirated using conventional suction. With this technique, the average volume returned from a normal, non-smoking individual is $50-70 \%$ with recovery of $5-10 \times 10^{6}$ cells and $1-10 \mathrm{mg}$ protein. ${ }^{7}$

Comparison of the effector cells recovered by lavage to those present in open lung biopsies has shown that the cell populations recovered by lavage accurately reflect the population of effector cells present in the alveolar structures. ${ }^{36}$ This is not surprising since for a standard lavage, approximately $98 \%$ of the epithelial surface "seen" by the lavage fluid is alveolar - that is, the contribution by bronchi is negligible. The only caveat modifying this concept is that bronchoalveolar lavage only reflects the effector cell populations in the alveolar structures when no inflammatory airway disease exists. In the presence of bronchial inflammation, it is impossible to tell whether the effector cells are airway or alveolar derived.

Importantly, bronchoalveolar lavage is safe. ${ }^{37}$ We only lavage those individuals without significant heart disease or clotting disorder and require: an $\mathrm{FEV}_{1}>1$ litre, $\mathrm{PaO}_{2}>75 \mathrm{~mm} \mathrm{Hg}$ (with supplemental $\mathrm{O}_{2}$ ), and that the $\mathrm{PaCO}_{2}$ not be elevated. With these guidelines, prospective evaluation of individuals undergoing lavage demonstrated a complication rate of $<5 \%$. All complications were minor-for example, transient fever, bronchospasm, or nasal bleeding. In addition, bronchoalveolar lavage is readily accepted by patients as a routine method by which to evaluate their disease; over the past seven years we have had several patients who have had two to four lavage procedures each year.

It has been estimated that a standard $100 \mathrm{ml}$ lavage samples approximately $10^{6}$ alveoli. Thus, it is not surprising that for most situations, lavage analyses from different lobes yield similar results ${ }^{32}$ - that is, bronchoalveolar lavage gives a representative "average" picture of the status of the inflammatory and immune processes in the alveolar structure.

Quantification of the effector cell populations recovered by lavage is approached in two ways. ${ }^{7}$ Most commonly, the analysis is presented in a similar fashion to cell differentials in blood with each cell type presented as a percentage of the total cells recovered. Alternatively, the data are expressed as total numbers of alveolar macrophages recovered per $\mathrm{ml}$ of lavage fluid recovered.

There are advantages and conceptual dangers associated with both methods. In the "differential" method, 200-500 cells are usually counted and the proportion of each expressed. In normal, nonsmoking individuals, a typical cell differential reveals $93 \pm 5 \%$ macrophages, $7 \pm 1 \%$ lymphocytes, and $<1 \%$ polymorphonuclear leucocytes. ${ }^{?}$ In cigarette smokers with no evidence of lung disease, the cell differential is similar except that up to $5 \%$ neutrophils are present, with a proportionally decreased percentage of alveolar macrophages. ${ }^{138}$

In the "total cell" method, the cell differential is combined with the total cell count to quantify the total numbers of each cell type recovered per unit volume of fluid recovered. For example, in normal, non-smokers, a standard $100 \mathrm{ml}$ lavage yields approximately $10^{7}$ cells contained in $60 \mathrm{ml}$ of returned fluid. Assuming a cell differential of $90 \%$ macrophages and $10 \%$ lymphocytes, the total cells recovered would be $167 \times 10^{3} \mathrm{cells} / \mathrm{ml}$ with $150 \times$ $10^{3}$ macrophages $/ \mathrm{ml}$ and $17 \times 10^{3}$ lymphocytes $/ \mathrm{ml}$. In contrast, a typical "normal" cigarette smoker will yield the same return volume but containing three-fold more cells with a cell differential of $88 \%$ macrophages, $7 \%$ lymphocytes, and $5 \%$ neutrophils. 
This results in a yield of $501 \times 10^{3}$ cells $/ \mathrm{ml}$ including $441 \times 10^{3}$ macrophages $/ \mathrm{ml}, 35 \times 10^{3}$ lymphocytes, and $25 \times 10^{3}$ neutrophils $/ \mathrm{ml}$.

To the naïve observer, the total cell method has obvious advantages - it not only reveals a shift in the effector cells-for example, smokers have neutrophils-but also gives insight into the total number of effector cells present in the alveolar structures-for example, smokers have more macrophages and lymphocytes as well as neutrophils. This is particularly important concerning macrophages. When the data are expressed as total cells, the macrophages (along with many other effector cell types) are invariably increased in the interstitial lung diseases, making their importance apparent. However, since the macrophages represent $>90 \%$ of the cells present in the normal individual, if there is any shift toward another cell type (as is the case in most of the interstitial lung diseases) then the percentage of macrophages invariably decreases. Thus if the data are evaluated using only the differential method, this suggests (to the non-lavage aficionado) that the macrophages are less important to the overall alveolitis. However, as we will see below, macrophages are critical to the pathogenesis and staging of these disorders.

The validity of the "total cell" method, however, depends on the validity of quantifying the total number of cells per standard lavage. The problem is not in counting the total number of cells (this is easily done using routine laboratory methods), but rather in the variability in the volume returned.? While several series have shown that the average volume returned for groups of patients are similar, ${ }^{32} 3539$ there is significant variability (per standard $100 \mathrm{ml}$ lavage) within each group, in the same patient from segment to segment, and in the same segment from day to day. ${ }^{32}$ The reasons for this have not been studied in detail, but are probably associated with bronchial tone, the site of the equal pressure point relative to the position of the bronchoscope, the force at which the fluid is instilled, the length of time it is left in the distal lung, and the force of the vacuum used for aspiration. Furthermore, the volume returned is dependent on the disease statemuch less is returned from patients with lung destruction that from normal individuals. Because of this problem, the safest approach is to present the data as a cell differential. However, the total cell method may yield important insights into the intensity of the alveolitis and, until enough data are obtained worldwide to establish clear standards, it is worth using both methods.

Quantification of the noncellular constituents of lavage fluid presents even a more difficult problem than quantification of the cellular components. ${ }^{7} 3940$
Ideally, it would be desirable to know the concentration of various proteins and mediators in the fluid lining the epithelium of the alveolar structures. Unfortunately, the epithelial fluid obtained is diluted to a variable amount by the saline used to recover it. Since the volume of fluid returned is variable, there are inherent dangers in expressing the noncellular components as "per ml" fluid. To circumvent this problem, most investigators use albumin as a standard to which noncellular components are compared. ${ }^{72} 4142$ Albumin is a midrange size serum component (69000 daltons) that easily diffuses through the lung yet is not synthesised or concentrated by lung. While using albumin as a reference point does not give the exact concentration of noncellular constituents in the alveolar structures, it does help to distinguish whether the noncellular component is derived from blood-for example, by diffusion-or whether it is produced in lung. For example, IgG in normal lavage fluid is similar to that present in blood. ${ }^{3241}$ In this context, if IgG/ albumin in lavage fluid is greater than that in serum, it is reasonable to hypothesise that IgG production in the alveolar structures is increased relative to that in blood. ${ }^{32} 41$

While this approach is the most rational available, it does not get around the problem of the circumstance where the actual concentration of albumin in the alveolar epithelial fluid is also increasedfor example, a chronic lung disease in which there are slightly "leaky" capillaries. In this circumstance, increased IgG levels in lung may be missed when lavage albumin levels are used as a reference point. Unfortunately, there is no currently acceptable way around this problem. In an analogous fashion to lavage cell analyses, it is probably best to evaluate the data both as per $\mathrm{mg}$ albumin and per $\mathrm{ml}$ fluid until more experience is available.

\section{GALLIUM-67 SCANNING}

This is a scintigraphic procedure which gives an overall estimate of the extent and intensity of inflammation in the alveolar structures. Gallium-67 $\left({ }^{67} \mathrm{Ga}\right)$ is a cyclotron produced isotope that, in the form of ${ }^{67} \mathrm{Ga}$-citrate, is known to localise in regions of inflammation. ${ }^{434}$ It is conventionally administered intravenously and the scan carried out two days later. Besides the radiation (approximately $1 \mathrm{rad} /$ scan; similar to that associated with a barium enema), there is no potential danger from this procedure. In over 10000 scans at the NIH, we have seen no allergic reactions to the material administered. Unlike bronchoalveolar lavage, gallium scanning can be carried out in the presence of active inflammatory airway disease; apparently the total mass of bronchi is too small to give a positive scan. ${ }^{44}$ 
Furthermore, since the scan procedure does not compromise lung function, patients who do not fit the minimal safety criteria for lavage can still undergo ${ }^{67} \mathrm{Ga}$ scanning.

In normal individuals, ${ }^{67} \mathrm{Ga}$ is not taken up in sufficient quantities within the alveolar structures to yield a positive scan. In patients with active interstitial lung disease, however, there is diffuse uptake of the isotope over broad areas of the lung parenchyma. ${ }^{44}$ It is now recognised that the mechanism of this accumulation of gallium- 67 in interstitial disease is the uptake of the isotope by active effector cells within the alveolar structures ${ }^{44} 45$ - that is, a positive gallium scan indicates the presence of activated inflammatory and immune effector cells within the lower respiratory tract. Recent studies have demonstrated that, in most instances, this reflects a high density of activated alveolar macrophages. ${ }^{45}$

The easiest approach to the ${ }^{67} \mathrm{Ga}$ scan is to simply read it as positive or negative. However, the amount of gallium-67 taken up by the parenchyma can also be quantified by visual or computerised methods. In this context, a "gallium- 67 index" can be generated which accounts for the area of lung involved as well as the intensity of each region of uptake. ${ }^{33}$ For example, assuming the liver to be $4+$ and a region of the abdomen to be 0 , a 0-4+ "intensity" scale can be constructed for each patient. Thus, if $50 \%$ of the lung is involved to an intensity of $3+$, the individual has $3 \times 50$ or 150 index units. Using such a method, normal individuals have 50 index units or less.

In evaluating ${ }^{67} \mathrm{Ga}$ scans, it is important to distinguish between lung parenchyma and hilar nodes. ${ }^{34} 44$ While the activity of the hilar nodes may be of interest in disorders such as sarcoidosis, it is the activity in the parenchyma that reflects the alveolitis and hence is relevant to the pathogenesis, staging, and therapy of the interstitial lung diseases.

\section{Inflammatory and immune processes in normal alveolar structures}

With the use of bronchoalveolar lavage, a great deal of information has accumulated concerning the effector cells and inflammatory and immune related mediators present in the normal human alveolar structures (see references 1 and 7 for comprehensive reviews). In normal, non-smoking individuals, the alveolar macrophage is the major effector cell present. Importantly, although this cell is capable of releasing a variety of inflammatory and immune mediators when activated, the macrophage population in normal lung is relatively quiescent. ${ }^{46}$ Consistent with this concept, the normal alveolar macrophage takes up little gallium-67 and normal individuals have negative gallium scans. ${ }^{33} 45$
The lymphocyte subpopulations of the normal lung are similar to that of peripheral blood. 7478 Of the lymphocytes present, $73 \pm 4 \%$ are $T$ cells and $8 \pm 3 \%$ are B cells. ${ }^{48}$ Of the T cells, $48 \pm 7 \%$ are helper cells and $25 \pm 5 \%$ are suppressor cells. ${ }^{48}$ Although the $T$ cell populations of the human lung are capable of being stimulated to produce a variety of lymphokines, they are not doing so when obtained from the normal individual. ${ }^{71} 49$ Of the B cell populations, $<1 \%$ are spontaneously producing immunoglobulins including IgG, IgM, IgA, and IgE. ${ }^{75051}$

Evaluation of the noncellular constituents present in normal lavage reveals that IgG and $\operatorname{IgA}$ are present in significant quantities but there is relatively little IgM. ${ }^{41}$ Components of the classic, alternative, and common complement pathways are present but there is very little $\mathrm{C} 5$, suggesting that a source of this component is necessary before the complement cascade can play an important role in the pathogenesis of lung disease. ${ }^{41}$ In addition to immunoglobulins and complement, a variety of other inflammatory and immune related molecules are present in alveolar structures. However, while such molecules (for example, $\alpha 1$ antitrypsin, ${ }^{5}$ myeloperoxidase, ${ }^{52}$ and histamine ${ }^{53}$ ) are probably involved in the pathogenesis of the interstitial disorders, their use in routine clinical evaluation of these patients has not been established.

\section{Inflammatory and immune effector processes in interstitial lung disease}

Bronchoalveolar lavage and gallium-67 scanning have demonstrated that, in general, the alveolitis of active interstitial disease is characterised by three features: (1) an increase in the total number of inflammatory and immune effector cells in the alveolar structures; (2) a shift in cell populations such that one or more effector cell types are emphasised in relation to others; and (3) an activation of one or more effector cell types. The activation of these effector cells is of critical importance to the pathogenesis of interstitial disease, as such cells have the potential to effect parenchymal toxicity, 465455 increase the population size of specific parenchymal cells, ${ }^{50}$ attract inflammatory and immune effector cells from the blood to the alveolar structures and activate these cells once they arrive, 485758 modulate granuloma formation, ${ }^{57}$ and derange the connective tissue matrix and modulate the fibrotic process. ${ }^{5659-61}$

The alveolitis of the interstitial disorders influences lung function in at least two ways. ${ }^{15}$ First, the effector processes of the cells comprising the alveolitis causes the cellular and matrix disorganisation of the alveolar structures that characterise these 
disorders-that is, changes in the type, number, and location of parenchymal cells, fibrosis and/or granulomata. Secondly, the alveolitis influences lung function just by irs presence since the cells comprising the alveolitis expand the interstitium and occupy space in the alveolar lumina normally occupied by gas. ${ }^{62}$ The specific effects of such physical deformations on lung function is unknown, but they probably influence critical mechanical processes involved in the respiratory cycle.

\section{Classification of interstitial lung disease using alveolitis parameters}

While all the interstitial lung diseases are associated with increased numbers of effector cells in the alveolar structures, groups of interstitial diseases can be characterised by the relative proportions of the different effector cell populations comprising the alveolitis. Currently, the alveolitis of the interstitial disorders is classified into two groups: neutrophilic and the lymphocytic.

\section{NEUTROPHILIC DISORDERS}

These disorders are characterised by an alveolitis comprised of macrophages, lymphocytes, and neutrophils. The best characterised is idiopathic pulmonary fibrosis; ${ }^{3} 41$ a typical patient with active disease has an alveolitis consisting of a five-fold increase in the number of alveolar macrophages and lymphocytes together with an accumulation of neutrophils. The numbers of neutrophils present are not trivial; they represent $5-50 \%$ of all effector cells recovered; that is, assuming $5 \times 10^{7}$ cells and a $60 \%$ return of a $100 \mathrm{ml}$ lavage, these represent $42 \times 10^{3}$ to $417 \times 10^{3}$ neutrophils/ml recovered. Other diseases known to have an alveolitis with an emphasis on neutrophils include familial pulmonary fibrosis (a disease similar to IPF with an autosomal dominant inheritance), ${ }^{6364}$ the chronic interstitial lung diseases associated with the collagen-vascular disorders, ${ }^{732} 41$ histiocytoxis-X, ${ }^{132}$ and asbestosis. ${ }^{7} 6566$

While all effector cells comprising the alveolitis undoubtedly play a role in the derangement to the alveolar structures that characterise IPF, the presence of the neutrophil is paramount. ${ }^{5}$ The neutrophil is a short-lived cell that, within a short time after reaching the lung, releases a potent armamentarium of inflammatory mediators (such as oxidants and connective tissue specific proteases) that can injure parenchymal cells and disorganise the extracellular matrix. ${ }^{7}$ Furthermore, by virtue of the chronicity of the alveolitis (we have seen patients with IPF in which neutrophils comprise greater that $25 \%$ of all effector cells for over three years), the IPF lung is constantly under attack by effector cells with the potential to significantly derange the alveolar structures. In this context, it is no wonder that, on the average, IPF is the most rapidly progressive of the interstitial disorders. ${ }^{1}$

Since neutrophils are blood cells not normally found in alveolar structures, there must be a mechanism by which they are chronically attracted to the alveolar structures in diseases like IPF. Interestingly, although the complement system is classically thought to play a role in neutrophil attraction (mostly through C5a, a complement fragment that is chemotactic for neutrophils), there is no evidence that the complement system is involved in the chemotaxis of blood neutrophils in those chronic interstitial lung diseases characterised by a neutrophil alveolitis. ${ }^{94167}$ In those diseases studied, the source for the neutrophil attraction seems to be the alveolar macrophage, a cell that when appropriately stimulated, releases a chemotactic factor that is relatively specific for neutrophils. ${ }^{68}$ For some interstitial lung diseases, the stimulus that activates the macrophage to release this chemotactic factor is known. In IPF and familial pulmonary fibrosis the stimulus is locally produced immune complexes produced within the alveolar structures $;{ }^{58}$ these complexes activate the macrophage through its IgG Fc receptor. ${ }^{58} 68$ In asbestosis, the stimulus is the asbestos particle itself; 29 when macrophages attempt to ingest the asbestos they are activated to release the neutrophil chemotactic factor.

Thus, the alveolitis of the neutrophil disorders seems to have two components: increased numbers of activated macrophages and large numbers of neutrophils. In this regard, if the alveolitis theory of interstitial lung disease is correct, it is reasonable to hypothesise that individuals with neutrophil disorders that have a high intensity alveolitis (that is, large numbers of activated macrophages and neutrophils) will deteriorate while those with low intensity alveolitis (that is, small numbers of activated macrophils and neutrophils) will not. In IPF, this hypothesis has been substantiated by studies in both Britain and USA. Haslam et $a l^{69}$ have demonstrated that those with larger proportions of neutrophils clearly do more poorly than those with low numbers of neutrophils. Likewise, Keogh et al ${ }^{70}$ have shown that over one year, if neutrophils represent greater than $10 \%$ of the effector cells present and if the gallium scan is positive (that is, larger numbers of activated macrophages) then $45 \%$ of patients with IPF will deteriorate in at least two functional parameters such as vital capacity, total lung capacity, or diffusing capacity. In contrast, with low intensity alveolitis (that is, less than $10 \%$ neutrophils or negative gallium scan), less than $10 \%$ of patients will deteriorate. 
In addition to predicting deterioration in diseases like IPF, the presence of a neutrophil alveolitis can be used to identify individuals in the earliest stages of their disease. For example, recent studies by Bitterman et al ${ }^{64}$ have shown that in families with familial pulmonary fibrosis, a neutrophil alveolitis occurs before any evidence of lung dysfunction.

\section{LYMPHOCYTIC DISORDERS}

In contrast to the neutrophilic disorders, the alveolitis of the lymphocytic disorders is distinguished by large numbers of macrophages and lymphocytes without neutrophils. ${ }^{73241}$ Whereas lymphocytes comprise $\leqslant 10 \%$ of the normal effector cell populations in the neutrophilic disorders, lymphocytes represent at least $15 \%$, and usually more, of the cells making up the alveolitis of the lymphocytic disorders. ${ }^{32}$ Moreover, for all those lymphocytic disorders characterised to date, the expanded lymphocyte populations are primarily $T$ lymphocytes. ${ }^{7} 4149$

The best characterised lymphocytic disorder is sarcoidosis. ${ }^{4}$ The alveolitis of a typical patient includes a five-fold increase in number of macrophages and lymphocytes together with a relatively expanded proportion of $\mathrm{T}$ lymphocytes. Thus, a standard $100 \mathrm{ml}$ lavage of a patient with active pulmonary sarcoidosis will contain $60 \%$ macrophages and $40 \%$ lymphocytes with $\mathrm{T}$ lymphocytes representing $36 \%$ of all cells recovered (normally $\mathrm{T}$ cells represent $<7 \%$ of all cells recovered). In terms of total cells, assuming that $5 \times 10^{7}$ cells and $60 \mathrm{ml}$ of fluid were recovered, this would represent $500 \times 10^{3}$ macrophages $/ \mathrm{ml}$ recovered and $300 \times 10^{3} \mathrm{~T}$ cells $/ \mathrm{ml}$ recovered. In the context that lavage of a normal individual contains at most $10 \times 10^{3} \mathrm{~T}$ cells $/ \mathrm{ml}$ fluid recovered, ${ }^{7}$ it is obvious, therefore, that sarcoid is clearly a disease characterised by marked expansion of the lung $\mathrm{T}$ cell populations. ${ }^{4}$

Lung $T$ lymphocytes play a critical role in the pathogenesis of sarcoidosis. Not only is the alveolitis characterised by an increase in number of $\mathrm{T}$ cells, but the $T$ cell populations are altered such that there is a relative expansion of the proportions of $T$ helper cells and a decreased proportion of $T$ suppressor cells. ${ }^{48}$ Of paramount importance, these lung T cell populations are activated and release lymphokines such as monocyte chemotactic factor and migration inhibitory factor. ${ }^{4} 57$ Both products are important in granuloma formation. Monocyte chemotactic factor attracts monocytes to the alveolar structures while migration inhibitory factor immobilises the cells and activates them. ${ }^{4} 57$ Since monocytes are the building blocks of granuloma formation, this explains one important aspect of this disease. In addition, the lung $T$ cells in sarcoidosis are nonspecifically releasing "helper factors" that stimulate lung B cells to produce immunoglobulin in a polyclonal fashion. ${ }^{71}$ While this may not be important in terms of pathogenesis, it explains to a large extent the mechanisms of the hypergammaglobinaemia of this disease - that is, the increased immunoglobulins found in blood are derived from lung B cells stimulated by lung $\mathrm{T}$ cells.

The mechanism of the expansion of $\mathrm{T}$ cell numbers and of the state of their activation are not fully understood in sarcoidosis, but the alveolar macrophage seem to play a major role. These patients have markedly positive gallium scans and thus a high density of activated alveolar macrophages. ${ }^{45}$ Interestingly, however, the macrophages of the sarcoidosis lung seems to be activated in a fashion different from that in idiopathic pulmonary fibrosis. While IPF macrophages produce neutrophil chemotactic factor, ${ }^{58}$ sarcoidosis macrophages instead release interleukin-1, a factor that expands the numbers of $\mathrm{T}$ cells. ${ }^{72}$

Macrophage $T$ cell interactions at sites of disease activity in sarcoidosis may explain the mechanism of increased serum angiotensin converting enzyme in these patients. Recent studies suggest that activated $T$ cells will stimulate cells of the mononuclear phagocyte series to produce angiotensin converting enzyme ${ }^{73}$ the increased presence of this enzyme in serum may reflect this process.

Although most of the information regarding the lymphocytic disorders deals with sarcoidosis, it is recognised that all the classic granulomatous disorders, including hypersensitivity pneumonitis ${ }^{41}$ and berylliosis, ${ }^{74}$ are characterised by an alveolitis that includes increased numbers of macrophages and lymphocytes with relatively expanded proportions of activated $T$ lymphocytes.

Like the type of analyses performed for IPF, it is reasonable to suggest that individuals with lymphocytic disorders with high intensity alveolitis will deteriorate more rapidly than those with low intensity alveolitis. In untreated patients with sarcoidosis, this is clearly the case. While the vast majority of patients with $\mathrm{T}$ cells greater than $28 \%$ and positive gallium scans deteriorate over a six-month period, less than $8 \%$ of patients with $\mathrm{T}$ cells less than $28 \%$ and/or negative gallium-67 scan will worsen their lung function over the same period. ${ }^{75}$

\section{MIXED DISORDERS}

Classification of the interstitial lung disorders by virtue of lavage-defined alveolitis criteria will undoubtedly undergo revision as more patients are studied. In fact, minor exceptions to the neutrophilic and lymphocytic classification are already known. Roth et al have shown that in the late stages of sarcoidosis, when there is cystic disease and 
fibrosis, neutrophils can be present. ${ }^{76}$ Furthermore, the Brompton group have noted that, in a rare patient with IPF, lymphocytes can rarely represent $>10 \%$ of the effector cells present.6977 This observation is of interest since this minor shift in effector cell populations may represent a very early phase of the alveolitis. If so, it will not be surprising if such patients have a better prognosis.

Eosinophils may also be an important component of the alveolitis of the interstitial lung disease. While the roles of the eosinophil in such diseases have not been clarified, Davis et $^{\text {al }}{ }^{78}$ have recently demonstrated that eosinophils carry a collagenase capable of deranging human lung collagen and are capable of destroying a variety of lung parenchymal cells, including epithelial cells and fibroblasts. Eosinophils are clearly present in a variety of disorders, particularly the neutrophilic disorders such as IPF. ${ }^{724169}$ It is also likely that at least some patients with disorders such as chronic eosinophil pneumonia, and perhaps the drug induced diseases, will be characterised by eosinophils dominating the alveolitis. If so, it may be useful to develop the "eosinophilic disorders" as another category of the alveolitis of the interstitial lung diseases.

\section{Noncellular components of the alveolitis of the interstitial lung diseases}

While the effector cell populations are the most direct means by which to characterise the alveolitis of the interstitial lung diseases, analyses of the cellular fluid constituents of bronchoalveolar lavage permits evaluation of the results of the alveolitis, that is, the various proteins and other mediators released by the activated effector cells comprising the alveolitis. There are numerous examples of this including increases in immunoglobulins in most diseases $;^{7} 79$ presence of active collagenase in IPF;61 increase in histamine in IPF ${ }^{53}$ increases in fibronectin in most diseases; ${ }^{59}$ and the presence of immune complexes in IPF. ${ }^{58}$ However, while these findings represent a goldmine for those interested in the pathogenesis of these disorders, clear guidelines have not been established concerning their use in diagnosing, staging, and treating patients.

\section{From laboratory to bedside - use of alveolitis parameters in staging and treating patients with interstitial lung disease}

The central role of alveolitis to the interstitial lung diseases is clear. It is obvious, therefore, that the most rational way to stage these patients and make therapy decisions is to evaluate the alveolitis to determine its character and intensity. This, however, is easier said than done. In general, the alveolitis of the interstitial disorders represents effector processes localised to the lung - that is, they are not reflected systemically. Thus, routine clinical parameters (such as blood tests) are generally not useful in making decisions concerning the status of the alveolitis. ${ }^{134}$ Furthermore, although it seems rational to use the chest radiograph and lung function testing to stage these patients and make decisions on treatment, comparison of these tests with open lung biopsies have shown that they bear little relationship to the status of the alveolitis. ${ }^{16} 81-83$ Thus, while the x-ray and pulmonary function test can indicate the overall state of these patients, they are more useful in staging the overall derangements to the alveolar structure than in staging disease activity. They tell what has occurred before, not what is happening at the time of evaluation.

To stage the alveolitis accurately, the clinician must go directly to the site of disease-the alveoli. To do so, he must use tests that directly monitor the status of the alveolitis-bronchoalveolar lavage and gallium scanning. We now use both parameters to make routine clinical judgements. For a patient with high intensity alveolitis, we start treatment. If the patient is already under treatment, we use more aggressive therapy. For an individual with low intensity alveolitis, we follow the patient but do not treat; if they are currently under therapy, we taper it.

Two questions are frequently asked in relation to this approach. First, do you need both bronchoalveolar lavage and gallium scanning? Second, if a patient has high intensity alveolitis, is it necessary to start therapy immediately or can you wait to see if the alveolitis will subside spontaneously?

The answer to the first question is-we do not know. For routine clinical practice, the gallium scan is probably the best way to assess the intensity of the activated alveolar macrophages while bronchoalveolar lavage is the best method to assess lymphocytes and neutrophils. Our current data suggest the use of both parameters increases accuracy significantly, but the final answers are not yet in. If the patient has coexisting inflammatory airway disease, (for example, from cigarette smoking) there is no choice-lavage is not as useful as gallium-67 scanning. Likewise, if the patient does not fit the guidelines for bronchoalveolar lavage, ${ }^{37}$ gallium-67 scanning is the only option. However, in most circumstances, lavage is more sensitive and yields more information. Thus, if only one test can be used, lavage is probably the best choice.

The answer to the second question is not definitively known but guidelines are beginning to emerge, at least for IPF and sarcoidosis. For IPF, the alveolitis is so potent that therapy is usually begun as soon 
as high intensity alveolitis is detected. For sarcoidosis, high intensity alveolitis is almost invariably followed by a deterioration in at least one functional parameter over the subsequent six months. It is not clear, however, what happens in the long term. For now, therefore, we usually observe such an individual for two to three months; if the high intensity alveolitis persists, we then start therapy.

Where to from here? Undoubtedly, lavage and gallium-67 scanning will yield an enormous amount of new information concerning the interstitial lung diseases. Use of these methods have already shown that alveolitis is the key to these diseases and it is likely that both lavage and gallium67 scanning will prove invaluable in making rational staging and therapy decisions. This is welcome news for a group of disorders that have previously been frustrating to the physician and often fatal to the patient.

BRENDAN A KEOGH
RONALD G CRYSTAL
Pulmonary Branch
National Heart, Lung and Blood Institute
Bethesda
Maryland
USA

\section{References}

${ }^{1}$ Keogh BA, Crystal RG. Chronic interstitial lung disease. In: Simmons DH, ed. Current pulmonology, Vol 3. New York: Wiley, $1981: 237-340$.

${ }^{2}$ Fulmer JD, Crystal RG. Interstitial lung disease. In: Simmons DH, ed. Current pulmonology. Vol 1. Boston: Houghton Mifflin, 1979:1-65.

${ }^{3}$ Crystal RG, Fulmer JD, Roberts WC, Moss ML, Line BR, Reynolds HY. Idiopathic pulmonary fibrosis: clinical, histologic, radiographic, physiologic, scintigraphic, cytologic, and biochemical aspects. Ann Intern Med 1976; 85:769-88.

${ }^{4}$ Crystal RG, Roberts WC, Hunninghake GW, Gadek JE, Fulmer JD, Line BR. Pulmonary sarcoidosis: a disease characterized and perpetuated by activated lung $\mathrm{T}$ lymphocytes. Ann Intern Med 1981 ;94:73-94.

${ }^{5}$ Crystal RG, Gadek JE, Ferrans VJ, Fulmer JD, Line BR, Hunninghake GW. Interstitial lung disease: current concepts of pathogenesis, staging, and therapy. $\mathrm{Am} \mathrm{J}$ Med $1981 ; 70: 542-68$.

${ }^{6}$ Keogh BA, Crystal RG. Pulmonary function testing in interstitial pulmonary disease: what does it tell us? Chest $1980 ; 78: 856-65$.

7 Hunninghake GW, Gadek JE, Kawanami O, Ferrans VJ, Crystal RG. Inflammatory and immune processes in the human lung in health and disease: evaluation by bronchovascular lavage. Am J Pathol 1979;97:149-206.

${ }^{8}$ Hunninghake GW, Keogh BA, Gadek JE, Bitterman PB, Rennard SI, Crystal RG. Inflammatory and immune characteristics of idiopathic pulmonary fibrosis. In: Buckley RH, Boniach D, Fahey JL, Parker CW, Rosse WF, Frankin EC, eds. Clinical immunology update. Vol III. New York: Elsevier-North Holland, 1982 : in press.
${ }^{9}$ Hunninghake GW, Crystal RG. Inflammatory and immune mechanisms in chronic diseases of the lung parenchyma. In: Siskin W, ed. Proceedings of the 6th Irwin Strasburger Memorial Seminar on Immunology. 1982: in press.

${ }^{10}$ Crystal RG, Hunninghake GW. Inflammatory and immune processes in the normal human lung. In: Siskin W, ed. Proceedings of the 6th Irwin Strasburger Memorial Seminar on Immunology. 1982: in press.

11 Fibrosing alveolitis. (Editorial) Br Med J 1964;1:464.

${ }^{12}$ Scadding JG. Fibrosing alveolitis. $\mathrm{Br}$ Med J 1964;2:686.

${ }^{13}$ Carrington CB, Gaensler EA, Mikus JP, Schachter AW, Burke GW, Croff AM. Structure and function in sarcoidosis. Ann N Y Acad Sci 1976;279:265-82.

${ }^{14}$ Rosen Y, Amorosa JK, Mason S, Cohen J, Lyons HA. Occurrence of lung granulomas in patients with stage 1 sarcoidosis. Am J Roentgenol 1977;129:1083-985.

15 Takahashi M. Histopathology of sarcoidosis and its immunological basis. Acta Pathol 1970;20:171-82.

${ }^{16}$ Teilum G. Morphogenesis and development of sarcoid lesions: similarities to the group of collagenesis. Acta Med Scand 1964;425:8-14.

17 Judd RA, Finnegan P, Curran RC. Pulmonary sarcoidosis: a clinicopathologic study. J Pathol 1975;115:191-8.

${ }^{18}$ Rosen Y, Athanassiades TJ, Moon S, Lyons HA. Nongranulomatous interstitial pneumonitis in sarcoidosis: relationship to the development of epithelioid granulomas. Chest 1978;74:122-5.

${ }^{19}$ Lacronique J, Bernaudin JF, Soler P, Lange F, Kawanami O, Sammon G, Georges R, Basset F. Alveolitis and granulomas: sequential course in pulmonary sarcoidosis. In: Proceedings of the 9th International Conference on Sarcoidosis, Paris, 1981.

${ }^{20}$ Carrington CB, Gaensler EA, Coutu RE, Fitzgerald MX, Gupta RG. Natural history and treated course of usual and desquantative interstitial pneumonia. $N$ Engl $J$ Med 1978;298:801-9.

${ }^{21}$ Hinson KFW. Diffuse pulmonary fibrosis. Hum Pathol $1970 ; 1: 275-88$.

${ }^{22}$ Schlueter DP. Response of the lung to inhaled antigens. Am J Med 1974;57:476-92.

${ }^{23}$ Barrowcliff DF, Arblaster PG. Farmer's lung: a study of an acute fatal case. Thorax 1968;23:490.

${ }^{24}$ Selikoff IJ, Lee DHK, Characteristics and Etiology of parenchymal Asbestosis. In: Asbestosis and disease. New York: Academic Press, 1978:143-67

${ }^{25}$ Zimmerman PV, Sinclair RA. Rapidly progressive fatal silicosis in a young man. Med J Austr 1977;2:704-6.

${ }^{26}$ Buechner HA, Ansari A. Acute silico-proteinosis: a new pathologic variant of acute silicosis in sandblasters, characterized by histologic features resembling alveolar proteinosis disease. Chest 1969;55:I274-84.

${ }^{27}$ Cervautes-Perez $\mathrm{P}$, Toro-Pereza $\mathrm{H}$, Rodriguez-Jurado $\mathrm{P}$. Pulmonary involvement in rheumatoid arthritis. JAMA 1980;243:1715-9.

${ }^{28}$ Dodson RF, Hurst GA, Williams MG Jr. Short-term response of lung parenchyma following "amosite" asbestos exposure. Am Rev Respir Dis 1980;121:232

29 Schoenberger CI, Hunninghake GW, Gadek JE, Crystal RG. Inflammation and asbestosis: characterization and maintenance of alveolitis following acute asbestos exposure. Chest 1981; (suppl.) 70S-71S.

${ }^{30}$ Lugano EM, Danber JH, Daniel RP. Silicia stimulation of chemotactic factor release by alveolar macrophage. $\mathrm{Am}$ Rev Respir Dis 1980;121:81.

${ }^{31}$ Bernardo J, Hunninghake GW, Gadek JE, Ferrans VJ, Crystal RG. Acute hypersensitivity pneumonitis: serial changes in lung lymphocyte subpopulations after exposure to antigen. Am Rev Respir Dis 1979;120:985-94.

${ }^{32}$ Weinberger SE, Kelman JA, Elson NA, Young RC Jr, 
Reynolds HY, Fulmer JD, Crystal RG. Bronchoalveolar lavage in interstitial lung disease. Ann Intern Med 1978; $89: 459-66$.

${ }^{33}$ Line BR, Fulmer JD, Reynolds HY, Roberts WC, Jones AE, Harris EK, Crystal RG. Gallium-67 citrate scanning in the staging of idiopathic pulmonary fibrosis: correlation with physiologic and morphologic features and bronchoalveolar lavage. Am Rev Respir Dis 1978;118: 355-65.

${ }^{34}$ Line BR, Hunninghake GW, Keogh BA, Jones AE, Johnston GS, Crystal RG. Gallium-67 scanning to stage the alveolitis of sarcoidosis: correlation with clinical studies, pulmonary function studies, and hronchoalveolar lavage. Am Rev Respir Dis 1981;123: 440-6.

${ }^{35}$ Reynolds HY, Newball HH. Analysis of proteins and respiratory cells obtained from human lungs by bronchial lavage. J Lab Clin Med 1974;84:559-73.

${ }^{36}$ Hunninghake GW, Kawanami O, Ferrans VJ, Young RC Jr, Roberts WC, Crystal RG. Characterization of the inflammatory and immune effector cells in the lung parenchyma of patients with interstitial lung disease. Am Rev Respir Dis 1981;123:407-12.

${ }^{37}$ Strumpf IJ, Feld MK, Cornelius MJ, Keogh BA, Crystal RG. Safety of fiberoptic bronchoalveolar lavage in the evaluation of the interstitial lung diseases. Chest 1981; 80:268-71.

38 Hunninghake G, Gadek J, Crystal R. Mechanisms by which cigarette smoke attracts polymorphonuclear leukocytes to lung. Chest 1980;77:273.

${ }^{39}$ Reynolds HY, Merrill WW. Pulmonary immunology; humoral and cellular immune responsiveness of the respiratory tract. In: Simmons DH, ed. Current pulmonology. Vol 3. New York: Wiley, 1981:381-422.

${ }^{40}$ Gadek JE, Klein H, Holland PV, Crystal RG. Replacement therapy of alpha 1-antitrypsin deficiency: reversal of protease-antiprotease imbalance within the alveolar structures of PiZZ subjects. J Clin Invest $1981 ; 68: 1277$ 88.

${ }^{41}$ Reynolds HY, Fulmer JD, Kazmierowski JA, Roberts WC, Frank MM, Crystal RG. Analysis of bronchoalveolar lavage fluid from patients with idiopathic pulmonary fibrosis and chronic hypersensitivity pneumonitis. J Clin Invest 1977;59:165-75.

42 Reynolds HY, Merrill WW. Analysis of bronchoalveolar lavage in normal humans and patients with diffuse interstitial lung diseases. In: Biserte G, Chretien J, Viisiu C, eds. Proceedings of an international Inserm symposium on bronchoalveolar lavage in man. Paris: Editions Inserm, 1979;84:227-50.

${ }^{13}$ Lavander PJ, Lowe J, Barker JR, Burn JI, Chaudri MA. Gallium-67 citrate scanning in neoplastic and inflammatory lesions. Br J Radiol 1971;44:361.

14 Line BR, Hunninghake GW, Keogh BR, Crystal RG. Gallium-67 scanning as an indicator of the activity of sarcoidosis. In: Fanburg BL, Dekker M, eds. Sarcoidosis and other granulomatous diseases of the lung. 1982: in press.

${ }^{45}$ Hunninghake GW, Line BR, Szapiel SV, Crystal RG. Activation of inflammatory cells increases the localization of gallium-67 at sites of disease. Clin Res $1981 ; 49$ : $171 \mathrm{~A}$.

${ }^{46}$ Hunninghake GW, Gadek JE. Szapiel SV et al. The human alveolar macrophage. In: Harris CC, Trump BF, Stoner GD, eds. Methods of cell biology. Vol $21 \mathrm{~A}$. New York: Academic Press, 1980:95-112.

${ }^{47}$ Hunninghake GW, Fulmer JD, Young RC, Williams WJ, Davis BH, Crystal RG. Comparison of lung and blood lymphocyte subpopulations in pulmonary sarcoidosis.
In: Proceedings of the 8th international conference on sarcoidosis and other granulomatous disease. London: Alpha Omega Publishing, 1980:426-35.

${ }^{48}$ Hunninghake GW, Crystal RG. Pulmonary sarcoidosis: a disorder mediated by excess helper T-lymphocyte activity at sites of disease activity. $N$ Engl J Med 1981; 8:429-34.

${ }^{49}$ Hunninghake GW, Fulmer JD, Young RC, Gadek JE, Crystal RG. Localization of the immune response in sarcoidosis. Am Rev Respir Dis 1979;120:49-57.

${ }^{50}$ Lawrence EC, Blease RM, Martin RR, Stevens PM. Immunoglobulin secreting cells in normal human bronchial lavage fluids. J Clin Invest 1978;62:832-5.

${ }^{51}$ Hunninghake GW, Schmit N, Rust M, Gadek JE, Keogh BA, Strumpf IJ, Crystal RG. Lung immunoglobulin production in a chronic lung disease. Clin Res 1979;27: 493A.

52 Gadek J, Hunninghake G, Crystal R. Unpublished observations.

${ }^{53}$ Haslam PL, Cromwell D, Dewar A, Turner-Warwick M. Evidence of increased histamine levels in lung lavage fluids from patients with cryptogenic fibrosing alveolitis. Clin Exper Immunol 1981 ;44:587-93.

${ }^{54}$ Martin WJ II, Gadek JE, Hunninghake GW, Crystal RG. Oxidant injury of lung parenchymal cells. J Clin Invest $1981 ; 68: 1277-88$.

${ }^{55}$ Davis WB, Hunninghake GW, Crystal RG. Cytotoxicity of eosinophils for lung parenchymal cells. Clin Res 1981; 49:445A.

${ }^{56}$ Bitterman PB, Crystal RG. Pulmonary alveolar macrophages (AM) secrete a growth factor (GF) causing human lung fibroblasts to replicate. Am Rev Respir Dis 1981; 123:50.

${ }^{57}$ Hunninghake GW, Gadek JE. Young RC Jr., Kawanami O, Ferrans VJ, Crystal RG. Maintenance of granuloma formation in pulmonary sarcoidosis by T-lymphocytes within the lung. $N$ Engl J Med 1980;302:594-8.

${ }^{58}$ Hunninghake GW, Gadek JE, Lawley TJ, Crystal RG. Mechanisms of neutrophil accumulation in the lungs of patients with idiopathic pulmonary fibrosis. $J$ Clin Invest $1981 ; 68: 259-69$.

${ }^{59}$ Rennard SI, Hunninghake GW, Bitterman PB, Crystal RG. Production of fibronectin by the human alveolar macrophage: a mechanism for the recruitment of fibroblasts to sites of tissues injury in the interstitial lung diseases. Proc Natl Acad Sci 1981;78:7147-51.

so Janoff A, White R, Carp H. Lung injury induced by leukocytic proteases. Am J Pathol 1979;97:111-29.

61 Gadek JE, Kelman JA, Fells G et al. Collagenase in the lower respiratory tract of patients with idiopathic pulmonary fibrosis. $N$ Engl $J$ Med 1979;301:737-42,

${ }^{22}$ Weinberger SE, Crystal RG. Reactions of the interstitial space to injury. In: Fishman AP, ed. Pulmonary diseases. New York: McGraw-Hill, 1979:640-7.

${ }^{63}$ Bitterman PB, Crystal RG. Is there a fibrotic gene? Chest 1980;78:549-50.

${ }^{64}$ Bitterman PB, Hunninghake GW, Keogh BA, Rossi G, Line BR, Crystal RG. Evidence for a locus regulating immune processes causing familial pulmonary fibrosis. Clin Res $1981 ; 49: 314$ A

${ }^{6}$ Bignon J, Atassi K, Jaurand MC, Geslin P, Solle R. Cellular and protein content of bronchoalveolar lavage fluid from patients with idiopathic pulmonary fibrosis and asbestosis. Am Rev Respir Dis 1978;117:56.

66 Gadek JE, Hunninghake GW, Schoenberger CI, Crystal RG. Pulmonary asbestosis and idiopathic pulmonary fibrosis: pathogenetic parallels. Chest 1981;80:(suppl) 63S-64S

${ }^{67}$ Robbins RA, Gadek JE, Crystal RG. Potential role of the 
complement system in propagating the alveolitis of idiopathic pulmonary fibrosis. Am Rev Respir Dis 1981; 123:50.

${ }^{68}$ Gadek JE, Hunninghake GW, Zimmerman RL, Crystal RG. Regulation of the release of alveolar macrophagederived neutrophil chemotactic factor. Am Rev Respir Dis 1980;121:723-33.

${ }^{69}$ Haslam PL, Turton CWG, Heard B et al. Bronchoalveolar lavage in pulmonary fibrosis: comparison of cells obtained with lung biopsy and clinical features. Thorax 1980;35:9-18.

${ }^{70}$ Keogh BA, Line BR, Rust M, Hunninghake GW, MeierSydow J, Crystal RG. Clinical stating of patients with idiopathic pulmonary fibrosis. Am Rev Respir Dis 1981; 123:89.

${ }^{71}$ Hunninghake GW, Crystal RG. Mechanisms of hypergammaglobulinemia in pulmonary sarcoidosis: site of increased antibody production and role of T-lymphocytes. J Clin Invest $1981 ; 67: 86-92$.

${ }^{72}$ Hunninghake GW, Broska P, Haber R, Keogh BA, Line BR, Crystal RG. Correlation of lung T-cell and macrophage function with disease activity in pulmonary sarcoid. Clin Res 1981;49:550A.

${ }^{73}$ Silverstein E, Friedland J, Shanek AE, Smith PR. Pathogenesis of sarcoidosis. Mechanism of angiotensinconverting enzyme (ACE) elevation: T-lymphocyte modulation of enzyme induction in mononuclear phagocytes: enzyme properties. In: Proceedings of the 9 th international conference on sarcoidosis and other granulomatous disorders. Paris, 1981.

${ }^{74}$ Moritz ED, Hunninghake GW, Crystal RG. Activation of lung immune effector cells: a possible precursor to beryllium lung disease. Am Rev Respir Dis 1981;123:140.
${ }^{75}$ Keogh B, Hunninghake G, Line B, Price D, Young R, Crystal R. Alveolitis parameters as predictors of the natural history of pulmonary sarcoidosis. Clin Res. 1981; 49:171A.

${ }^{76}$ Roth C, Huchon GJ, Arnoux A, Stanilas-Leguern G, Marsac JH, Chretien J. Bronchoalveolar cells in ad vanced pulmonary sarcoidosis. Am Rev Respir Dis 1981 ; 124:9-12.

77 Rudd RM, Haslam PL, Turner-Warwick M. Cryptogenic fibrosing alveolitis: relationship of pulmonary physiology and bronchoalveolar lavage to response to treatment and prognosis. Am Rev Respir Dis 1981;124:1-8.

${ }^{78}$ Davis WB, Gadek JE, Fells GA, Crystal RG. Role of eosinophils in connective tissue destruction. $A m$ Rev Respir Dis $1981 ; 126: 55$.

79 Reynolds HY. The importance of lymphocytes in pulmonary health and disease. Lung 1978;155:225-42.

${ }^{80}$ Gadek JE, Hunninghake GW, Zimmerman RL, Kelman JA, Fulmer JD, Crystal RG. Pathogenetic studies in idiopathic pulmonary fibrosis: control of neutrophil migration by immune complexes. Chest 1979;75S : 264S-265S.

${ }^{81}$ Carrington CB, Gaensler EA. Clinical-pathologic approach to diffuse infiltrative lung disease. In: Thurlbeck WM, Abell MR, eds. The lung: structure, function and disease. Baltimore: Williams and Wilkins, 1978:68-87.

${ }^{82}$ Epler GR, McCord TC, Gaensler EA. Normal chest roentenograms in diffuse infiltrative lung disease. $N$ Engl J Med 1978;298:934-9.

${ }^{83}$ Turner-Warwick M, Burrows B, Jonnson A. Cryptogenic fibrosing alveolitis: clinical features and their influence on survival. Thorax 1980;35:171-80. 